Does local government staff perceive digital communication with citizens as improved service?

Berger, Jesper B.; Hertzum, Morten; Schreiber, Trine Louise

Published in:

Government Information Quarterly

DOI:

10.1016/j.giq.2016.03.003

Publication date:

2016

Document version

Peer reviewed version

Citation for published version (APA):

Berger, J. B., Hertzum, M., \& Schreiber, T. L. (2016). Does local government staff perceive digital communication with citizens as improved service? Government Information Quarterly, 33(2), $258-269$. https://doi.org/10.1016/j.giq.2016.03.003 


\title{
Does Local Government Staff Perceive Digital Communication with Citizens as Improved Service?
}

\author{
Jesper B. Berger, Roskilde University, Denmark \\ Morten Hertzum, University of Copenhagen, Denmark \\ Trine L. Schreiber, University of Copenhagen, Denmark
}

\begin{abstract}
Digital communication between government and citizens is pivotal to e-government. The Danish egovernment initiative Digital Post aims to digitize all communication between government and citizens. We surveyed local government staff about how Digital Post affects the service delivered to citizens. As much as $82 \%$ of the 448 respondents considered digital communication with citizens using Digital Post a good idea, yet $47 \%$ reported concrete incidents in which they perceived a decrease in service with Digital Post. This result shows the importance of distinguishing between the overall service relationship and the concrete incidents of which the service consists. We discuss interactions between the relationship level and the incident level of Digital Post on the basis of a content analysis of the respondents' incident descriptions.
\end{abstract}

Keywords: E-government, digital communication, online services, technology adoption, local government, digital divide

\section{Introduction}

E-government encompasses "the use of information and communication technologies to enable citizens, politicians, government agencies, and other organizations to work with each other and to carry out activities that support civic life" (Robertson \& Vatrapu, 2010, p. 319). However, even in countries with a high level of e-government readiness, most of the communication consists of physical letters, phone calls, and face-to-face meetings. Digital communication between citizens and government agencies is not yet established practice (Andersen et al., 2011)., A transition to digital communication is necessary to attain the economic and efficiency benefits expected from egovernment. The perceived costs of imposing such a transition are debated and include that it degrades government service for less digitally literate citizens (Bélanger \& Carter, 2009). A service degradation may be experienced by citizens and by the government staff that is in direct contact with the citizens who are affected - positively or negatively - by the transition.

This study surveys local government staff's perception of the Danish e-government initiative Digital Post, especially of whether it is good service to citizens. Digital Post is a system for authenticating, encrypting, and sending digital letters between government institutions and citizens without the need for email addresses (which may change over time). Staff accesses Digital Post through an output manager. If a citizen has adopted Digital Post, the output manager sends a digital letter to the citizen using Digital Post; otherwise, the output manager automatically sends a physical letter. Digital Post is free of charge to citizens, who access it through a national public portal. We conducted our survey four years after local governments gradually started to use Digital Post and half a year before its use became mandatory for all citizens. 
We investigate Digital Post because it is pivotal to the national e-government strategy regarding digital communication between government and citizens and because only $27 \%$ of Danish citizens had become users of Digital Post a year before all citizens were required to use it (Berger \& Hertzum, 2014). The modest level of adoption among citizens makes it interesting to know how the system is perceived by the staff tasked with using it and, thereby, knowledgeable about its effects on the service delivered by local government to citizens. Next to the citizens, the staff is the largest user group of Digital Post, and the staff has an additional role as champions of the system toward the citizens. In spite of the importance of government-side users to e-government success, Rana et al. (2013) find that they are underrepresented in e-government research, which predominantly focuses on the citizens.

Studies of e-government mostly assess systems by asking users about their overall attitude toward the use of a system (e.g., Dwivedi et al., 2015; Rana \& Dwivedi, 2015). Far fewer studies assess systems by analyzing concrete incidents in the users' encounter with a system (e.g., Al Thunibat et al., 2011; Barbosa et al., 2013). While the users' relationship with a system consists of a series of incidents, the users' overall attitude may or may not reflect any concrete incident. Following studies in service research (Edvardsson \& Strandvik, 2000), we contend that the association between the relationship level and the incident level of an e-government service is complex and poorly understood. The aim of the present study is to survey local government staff's perception of Digital Post and to map out the sources underlying this perception. We assess local government staff's perception of Digital Post through survey questions about their attitude toward Digital Post. We map out the sources of their perception by asking them to describe a concrete incident with Digital Post and by qualitatively analyzing the variety of sources mentioned in these descriptions. By addressing the relationship level as well as the incident level the survey enables an analysis of the association between these two levels. More generally, the qualitative analysis adds richness to the constructs found in models of, for example, technology acceptance (Venkatesh et al., 2003) and service quality (Parasuraman et al., 2005).

In the next section we review related work on the perception and adoption of e-government and on the distinction between the relationship level and the incident level of services (Section 2). On this basis we describe the methodological considerations in devising and administering our survey (Section 3). In reporting the results of the survey, we start by analyzing the respondents' overall attitude toward Digital Post and contrasting it with the concrete incidents they report; then we content analyze the incidents (Section 4). The analysis leads to a discussion of whether digital communication between government and citizens, through systems such as Digital Post, is good service to the citizens (Section 5). We also discuss the implications and limitations of the study.

\section{Related work}

Governments are going online and increasingly make use of information technology in their internal processes and for communicating with citizens (Norris \& Reddick, 2013; Robertson \& Vatrapu, 2010). In the following, we briefly review related work on the perception and adoption of e-government and on the relationship and incident levels of services.

\subsection{The perception and adoption of e-government}

E-government research mostly reflects a perception that e-government brings changes that are positive for governments and citizens (Heeks \& Bailur, 2007; Janowski, 2015). This positive perception supports, and is supported by, the considerable government spending on e-government initiatives in many countries. A main result of the positive perception is the frequent proposition that e-government evolves through stages of increasing sophistication. While different stages have been proposed, the models share the characteristic that each increasingly sophisticated stage brings additional benefit. For example, Layne and Lee (2001) propose four stages: catalogue, involving online presence and downloadable forms; transaction, involving online services and forms; vertical 
integration, involving local systems that are linked to higher-level systems within a domain; and horizontal integration, involving the integration of systems across domains. The increasing sophistication of the stages implies that earlier stages tend to be prerequisites for later stages. Digital Post is at the transaction stage. Multiple studies find that the advancement of local governments to the transaction and integration stages is progressing slowly (Andersen et al., 2011; Norris \& Reddick, 2013). The transaction stage is critical for e-government adoption because this stage requires profound organizational changes, including privacy and security measures, re-engineering of backoffice processes, and new ways of working for staff (Irani et al., 2006). The slow progress has fostered studies of organizational barriers to e-government adoption (Dwivedi et al., 2012) and of how staff (Wastell et al., 2009) and citizens (Rana et al., 2015) perceive e-government.

Multiple studies investigate the perception of e-government among staff and citizens on the basis of factors drawn from models of technology acceptance (Venkatesh et al., 2003), diffusion of innovations (Rogers, 2003), service quality (Parasuraman et al., 2005), and web trust (McKnight et al., 2002). These studies aim to identify factors that are important to individual persons' perception of egovernment, and they assess the importance of a factor by its influence on whether a person adopts and uses e-government. In a survey of 873 US local public managers, Shin (2012) found that their use of e-government was influenced by their perception of the technology as well as by their commitment to public service. That is, consistent with technology acceptance models the use of egovernment was higher for managers who perceived the e-government technology as useful to their work and easy to use. At the same time, e-government use was higher for managers with a high commitment to provide public service (the seven items used to gauge this commitment included, e.g., "I consider public service my civic duty"). Similarly, Sun et al. (2006) found that staff satisfaction with a document-transfer system in the Taiwanese public sector was positively related to the staff's perception of system quality, information quality, and the quality of the service provided by internal IT staff. This study is particularly interesting because the document-transfer system resembles Digital Post.

Some studies find negative perceptions of e-government among staff. E-government services have been found to increase staff workload because the staff needs to spend more time documenting their work and following rigid workflows, thereby leading to disrupted work practices and growing resistance (Wastell et al., 2009). Government staff may face gaps between their mixed everyday experience of e-government services and the positive rationales that drive e-government at the institutional level. Roman (2013, p. 227) elaborates these gaps by emphasizing that "public administrators often develop personal and emotional ties with the citizens that they serve". These ties and the practical knowledge that follows from serving citizens provide the staff with an impetus to question and compensate for the rigid rules created by e-government. In most cases staff lacks the power to change the rules and must, therefore, work within or around them, probably experiencing moral tensions (Roman, 2013; Wastell et al., 2009). One source of such tensions is that equality of treatment may suffer as a result of e-government because some citizens cannot afford or master new technology (Bannister \& Connolly, 2014). A similar point of view is expressed by Dwivedi et al. (2012, p. 19) who argue that even though governments have succeeded with implementing egovernment, they might struggle with avoiding to exclude certain segments of the population such as "the elderly, disabled, less computer literate and poorer citizens". Irani et al. (2007) reported sources of tension that potentially affect the entire population, not just segments of it. The e-government practitioners studied by Irani et al. (2007, p. 331) were concerned about "the trend to dehumanize the interaction between citizens and government" and they questioned the evidence of citizens' demand for e-government. In addition, the practitioners often saw technology more as the creator than the solution of problems due to a poor fit between technology and work processes.

Because government staff's perception and adoption of e-government is influenced by whether it provides a quality service to citizens, it becomes relevant to this study how citizens perceive egovernment. In a meta-analysis of 103 studies, Rana et al. (2015) found that the most consistent 
predictors of citizens' attitude to e-government were their perception of its relative advantage, compatibility (with the citizen's existing values, beliefs, experiences, and needs), usefulness, and ease of use. Intention to use was predicted by a wider range of factors, which in addition to the most consistent predictors of attitude also included the citizens' perceptions of, for example, behavioral control, subjective norm, and risk. The three factors with the strongest, as opposed to most consistent, effect on intention to use were facilitating conditions, performance expectancy, and attitude. Shareef et al. (2011) surveyed 239 Canadian citizens and found that their adoption of egovernment depended on the sophistication of the e-government service. At a level of sophistication resembling Layne and Lee's (2001) first stage, catalogue, adoption was significantly affected by perceived awareness and ability to use. At a level of sophistication resembling Layne and Lee's second stage, transaction, adoption was, in addition, affected by perceived information quality, trust, and image. These results show that with increasing e-government sophistication, citizens' adoption became affected by a broader range of perceptions.

On the basis of the studies reviewed above, we envisage that the factors of, among others, the technology acceptance model will help explain local government staff's perception of Digital Post and that commitment to public service will be prominent among the sources underlying this perception. The studies reviewed so far have, however, not distinguished clearly between persons' overall perception of an e-government service and their perception of individual encounters with the service. We now turn to service research for a clarification of this distinction, which is important for understanding how perceptions are formed and how they can be assessed.

\subsection{The relationship level and incident level of services}

A service consists of a series of incidents during which the service provider and the service recipient interact, interspersed with periods without interaction (Parasuraman et al., 1988). Because services extend over time, they are often seen as relationships. To understand a service such as Digital Post, we need to understand how the concrete incidents and the overall relationship interact. From an assessment point of view, the relationship and the incidents constitute two distinct levels (Odekerken-Schröder et al., 2000). Relationship-level assessments target the service as a unit. This level lends itself to surveys asking respondents to rate their attitude toward a service, using questions such as 'Is Digital Post an easy-to-use service?' Surveys are fairly easy to administer and analyze but attitude ratings have been criticized for relying on preselected rating scales, which may miss important aspects of the respondent's perception of the service (Krosnick, 1999). Attitude ratings have also been criticized for forcing respondents to aggregate their service incidents into an overall attitude, which they may experience as unnatural and difficult (Stauss \& Weinlich, 1997), and for encouraging a tendency among respondents to agree to any assertion made in a question regardless of its content (Schaeffer \& Presser, 2003).

Incident-level assessments target the individual incidents of which the service relationship consists. Each incident is an encounter between the user and the service, for example between a citizen and Digital Post. Inspired by Flanagan (1954), the incident level of a service is often assessed by collecting descriptions of critical incidents and then conducting a content analysis to identify patterns in the data (Gremler, 2004). While the critical incident technique avoids the limitations of attitude ratings, it is time-consuming for respondents to describe critical incidents in concrete detail and for researchers to analyze the data. Consequently, "very few studies exceed 300 incidents for analysis" (Urquhart et al., 2003, p. 65). In addition, the critical incident technique has been criticized for disregarding the temporal aspect of services by restricting assessments to a usually small subset of the incidents in a service relationship (Stauss \& Weinlich, 1997). The critical incident technique has also been criticized for being susceptible to bias in respondents' recall and description of incidents because the method emphasizes a free account of the respondent's perspective (Gremler, 2004).

While the incidents experienced by a person over time result in her perception of the service relationship, it is not clear how assessments at the two levels are merged. Edvardsson and Strandvik 
(2000) investigated whether critical incidents were critical to the relationship and found that in spite of many cognitively negative incidents the respondents rated the relationship highly. Though the incidents did not seem to change the respondents' attitude to the service, they had told 4-5 other persons about the incidents, thereby suggesting that the incidents could have influenced these persons' perception of the service. Odekerken-Schröder et al. (2000) found that negative incidents had more influence on respondents' perception of a service relationship than positive incidents. This finding is consistent with the general finding in psychology that bad is stronger than good (Baumeister et al., 2001). Some authors equate the distinction between the relationship and incident levels with a distinction between service quality and satisfaction (Parasuraman et al., 1988). They argue that quality is a global judgment and, thereby, refers to the relationship level, whereas satisfaction relates to specific incidents. From this perspective, incident-level and relationship-level assessments should be considered complementary measurements, not alternatives: Attribute ratings provide an aggregate index of service quality (Stauss \& Weinlich, 1997); incident descriptions reveal the underlying sources of satisfaction and dissatisfaction (Bitner et al., 1990).

\section{Method}

To investigate local government staff's perception of Digital Post we conducted a survey addressing the relationship level as well as the incident level.

\subsection{The Digital Post system}

On the basis of a business case showing large savings in postal costs by shifting from physical to digital letters, the Danish government decided to introduce a system for authenticating, encrypting, and sending digital letters between government institutions and citizens. The system, Digital Post, was based on an existing system that had produced postal-cost savings in public and private companies sending large volumes of letters to citizens. Digital Post was launched in 2010 but its uptake among citizens was lower than expected. With the Digital Post law from 2012 (Law about Public Digital Post, 2012), the government made it mandatory for citizens to start using Digital Post no later than November 2014. The uptake among local governments was also low. To create an incentive for local governments to use Digital Post, their funding from central government was, from 2013, reduced with an amount corresponding to an estimated gradual increase in postal-cost savings. The estimate was adopted from the business case made by the Ministry of Finance (Ministry of Finance, 2012).

Danish local governments perform a range of tasks across various domains and supported by numerous information systems. System vendors were generally slow to offer integration with Digital Post. As a consequence, local government staff accesses Digital Post through a so-called output manager, rather than as an integrated component of their other information systems. Citizens access Digital Post through a national public portal, borger.dk, and can register for receiving notifications by conventional email or text messages, when they receive letters in Digital Post. For some citizens, the major incentives to adopt Digital Post are the gradual transition in society toward digital means of communication and the easier management of their correspondence with public institutions when all the correspondence is in one place. For other citizens, there may be no incentive - other than the status of Digital Post as mandatory.

\subsection{Survey instrument}

The survey instrument consisted of 29 questions, divided onto ten questions about the respondent's attitude toward Digital Post, three questions asking the respondent to describe a concrete incident with Digital Post, seven questions about the respondent's demographics and personal use of Digital Post, and nine questions not used in this analysis. See the appendix for the complete survey instrument. 
The ten attitude questions consisted of two questions about the respondent's overall attitude toward Digital Post and eight questions about specific attitude elements. The eight specific questions were adopted from the technology-acceptance literature (Venkatesh et al., 2003) and comprised two questions for each of performance expectancy, effort expectancy, social influence, and facilitating conditions. We asked the ten attitude questions to tap respondents' perception of Digital Post at the relationship level. Respondents answered the ten questions on five-point rating scales that ranged from 'agree' to 'disagree'.

The main question among the three incident questions asked the respondent to describe a concrete incident with Digital Post. The wording of this question was (translated from Danish):

Describe a concrete situation in which you have experienced that Digital Post changes the service delivered to the citizen. It may be a situation where your use of Digital Post has improved the service or decreased the service or a situation where you have refrained from sending Digital Post because you believed it would be bad service to the citizen.

We asked respondents to describe a concrete incident because we envisaged that the incident descriptions would be rich in detail about the sources of the respondents' perception of Digital Post and because the respondents' motivation to complete the survey might benefit from the possibility to recount a concrete incident from their experience with Digital Post. The open, incident-description question was followed by two closed questions. The first of these questions asked respondents about "The change in service to the citizen in the situation described" with the response options (a) improved service with Digital Post, (b) decreased service with Digital Post, and (c) the respondent had refrained from using Digital Post to avoid a decrease in the service delivered to the citizen. We also asked respondents how often the described incident occurred, providing five response options from 'very often' to 'very rarely'.

Finally, we asked respondents four questions about their weekly use of Digital Post and three demographic questions about their age, gender, and place of work. The weekly-use questions supplemented the attitude and incident questions with self-assessed quantifications of the amount of system use, indicated on a five-point scale with the response options ' 0 ', ' $1-5$ ', '5-10', '10-50', and ' $50+$ '. We used the demographic questions to analyze our data for response bias.

\subsection{Procedure}

The survey questions were formulated on the basis of two of the authors' previous research into the adoption of Digital Post (Berger \& Hertzum, 2014). We pilot tested the survey instrument on 100 people from the target population and, as a result, clarified the wording of a few questions. To inspire more elaborate descriptions we, in particular, revised the wording of the question asking respondents to describe a concrete incident with Digital Post.

The survey was conducted in April-May 2014 by emailing an invitation to participate to the members of $\mathrm{HK}$ who were registered to receive newsletters and the like. HK is the national union of commercial and clerical employees in Denmark. Except for distributing the invitation on our behalf, HK had no role in the survey. We had HK distribute the invitation to participate in the survey for three reasons. First, union membership is common in Denmark. Second, HK had approximately $72 \%$ of the clerical staff in local government as members. Third, it was the clerical staff that sent letters to citizens and, thereby, considered whether Digital Post was a more or less appropriate option than a physical letter. The invitation was sent to 16384 persons, only some of which were within our target group. Therefore, the invitation specified that it was only intended for clerical staff tasked with sending letters from local-government institutions to citizens and with receiving letters from citizens. The invitation also introduced the survey and contained a link to the survey itself.

Participation in the survey was fully anonymous, except if respondents were willing to be contacted for further details and therefore volunteered their contact details. No reminders were sent out. Our main reason for choosing against reminders was that we felt a reminder would increase the risk of 
some persons responding multiple times, something we would be unable to detect because the respondents were anonymous. We closed the survey after it had been running for 25 days.

\subsection{Data analysis}

We received 632 responses. Prior to our analysis we removed 100 responses with no, incomplete, or incomprehensible incident descriptions, 34 responses with incident descriptions that were not about Digital Post, 24 responses with incident descriptions about the use of Digital Post in communicating with companies rather than citizens, 19 responses from respondents who did not themselves communicate with citizens, and 7 other responses. As a result, our analysis comprised 448 responses.

The analysis of the incident descriptions consisted of identifying the categories of content in the incidents. The first and third author read the incident descriptions and annotated them with descriptive phrases. The descriptive phrases were then aggregated into an initial set of content categories. On the basis of these initial content categories the incidents were analyzed in an iterative process of coding incidents with already identified content categories and creating new categories to capture content not previously encountered. In this process, categories emerged, evolved, and recombined through discussions among the two authors and through the coding of still more incidents. At the end of this analysis, all incidents were coded with one or more of six content categories, see Table 1 . The incidents were coded with minimal interpretation by relying on the wording of the incident descriptions.

In preparation for a crosscheck of the analysis, the second author independently coded a training set of 93 randomly selected incident descriptions by assigning them to the six content categories. The authors then discussed the disagreements in their coding of the training set to arrive at a shared understanding of the categories. Thereafter, the second author independently coded the remaining 355 incidents. Cohen's (1960) kappa of the agreement between the original coding of the 355 incidents and the crosscheck was .64, which is above the recommended minimum of .60 (Lazar et al., 2010). With this indication that the coding of the incidents was fairly robust we elaborate the six content categories in Section 4.4 to map out the sources of the respondents' perception of Digital Post.

Table 1. The six content categories

\begin{tabular}{|c|c|}
\hline Category & Description \\
\hline $\begin{array}{l}\text { Changes in } \\
\text { service }\end{array}$ & $\begin{array}{l}\text { Changes - positive and negative - in the service toward the citizen after the } \\
\text { introduction of Digital Post }\end{array}$ \\
\hline $\begin{array}{l}\text { Attributes of the } \\
\text { citizen }\end{array}$ & $\begin{array}{l}\text { The citizen's prerequisites and readiness for using Digital Post, including skills, } \\
\text { motivation, and access to technology }\end{array}$ \\
\hline $\begin{array}{l}\text { Changes related } \\
\text { to staff }\end{array}$ & $\begin{array}{l}\text { Changes - positive and negative - in the local-government staff's perception of } \\
\text { their work situation as a consequence of Digital Post }\end{array}$ \\
\hline $\begin{array}{l}\text { Institution-level } \\
\text { effects }\end{array}$ & $\begin{array}{l}\text { Effects - positive and negative - for the local-government institution as such of } \\
\text { introducing Digital Post }\end{array}$ \\
\hline $\begin{array}{l}\text { Staff-related } \\
\text { operations }\end{array}$ & $\begin{array}{l}\text { Operations that are facilitated or hampered by the relation between Digital } \\
\text { Post and the local-government staff }\end{array}$ \\
\hline $\begin{array}{l}\text { Citizen-related } \\
\text { operations }\end{array}$ & $\begin{array}{l}\text { Operations that are facilitated or hampered by the relation between Digital } \\
\text { Post and the citizen }\end{array}$ \\
\hline
\end{tabular}

\subsection{Respondents}

To assess the representativeness of the 448 respondents we compared their age, gender, and geographic distributions with those of the full population of local government staff, see Table 2 . The 
data about the full population were obtained from the Ministry of Economic Affairs and the Interior. With respect to age and gender, the respondents were distributed similarly to the full population. For geographic distribution, the Capital Region of Denmark was overrepresented and the North Denmark Region underrepresented in our data; the percentages of respondents from the three other regions were similar to the full population. On this basis, we consider the respondents a reasonably representative sample of the population of local government staff. We acknowledge that our check for representativeness is restricted to age, gender, and geographic distribution and does not include, for example, job experience and general job satisfaction.

Table 2. Demographics of survey respondents compared with the population of local government staff

\begin{tabular}{|c|c|c|c|}
\hline \multirow[t]{2}{*}{ Category } & \multicolumn{2}{|c|}{ Survey respondents ${ }^{a}$} & \multirow{2}{*}{$\begin{array}{l}\text { Population of local } \\
\text { government staff }^{b} \\
\%\end{array}$} \\
\hline & $N$ & $\%$ & \\
\hline \multicolumn{4}{|l|}{ Age } \\
\hline Under 20 & 0 & 0 & 1 \\
\hline $20-29$ & 18 & 4 & 7 \\
\hline $30-39$ & 74 & 17 & 18 \\
\hline $40-49$ & 134 & 31 & 30 \\
\hline $50-59$ & 172 & 39 & 33 \\
\hline $60-69$ & 40 & 9 & 11 \\
\hline 70 and above & 0 & 0 & 0 \\
\hline \multicolumn{4}{|l|}{ Gender } \\
\hline Female & 386 & 86 & 84 \\
\hline Male & 61 & 14 & 16 \\
\hline \multicolumn{4}{|l|}{ Geographic region } \\
\hline Capital Region of Denmark & 87 & 22 & 11 \\
\hline Region Zealand & 91 & 23 & 21 \\
\hline Region of Southern Denmark & 87 & 22 & 21 \\
\hline Central Denmark Region & 107 & 27 & 31 \\
\hline North Denmark Region & 29 & 7 & 15 \\
\hline
\end{tabular}

Notes. ${ }^{a}$ Age was unspecified by 10 respondents, gender by 1 respondent, and region by 47 respondents. ${ }^{b}$ The data about the population of local government staff were obtained from the Ministry of Economic Affairs and the Interior (for the year 2013).

\section{Results}

We analyzed the responses to our survey from 448 clerical employees in Danish local-government institutions. The analysis addresses the respondents' perception of Digital Post at the relationship level as well as the incident level.

\subsection{Frequency of use of Digital Post}

The respondents reported using Digital Post to send digital letters to citizens at least as often as they sent physical letters to citizens, see Table 3.

The median frequency of use was about once a day for sending digital letters from the respondents' email client (Outlook) and about twice a day for sending digital letters from their text processing system via the output manager. The output manager could also be used without supplying the citizen's social security number but this practice meant that the letter could not be send digitally, effectively converting Digital Post into an alternative way of sending physical letters. The median frequency of this practice was non-use. We found a significant correlation between frequency of use 
and respondent age for only one type of use of Digital Post. Younger respondents made slightly more use of Digital Post via the output manager by supplying the citizen's social security number.

Table 3. Weekly use of Digital Post

\begin{tabular}{|c|c|c|}
\hline \multirow[t]{2}{*}{ How many times a week do you... } & Frequency $^{\mathrm{a}}$ & Correlation with age $^{\mathrm{b}}$ \\
\hline & Median & $\rho$ \\
\hline Use the Digital Post button in Outlook? & $1-5$ & .07 \\
\hline $\begin{array}{l}\text { Use [the output manager] with a social } \\
\text { security number? }\end{array}$ & $5-10$ & $-.13 * *$ \\
\hline $\begin{array}{l}\text { Use [the output manager] without a social } \\
\text { security number? }\end{array}$ & 0 & .06 \\
\hline Send a physical letter? & $1-5$ & -.02 \\
\hline
\end{tabular}

\subsection{Perception of Digital Post}

At the relationship level, $82 \%$ of the respondents agreed, fully or partially, that it was a good idea that local government wrote to citizens using Digital Post and $88 \%$ agreed, fully or partially, to the idea that citizens could write to government institutions using Digital Post, see Figure 1 . That is, the respondents' overall attitude toward Digital Post was, in general, positive. The median response was partial agreement for local government writing digitally to citizens and agreement for citizens writing digitally to local government. For both questions there was a significant, but weak, correlation with respondent age in that younger respondents agreed slightly more.

\begin{tabular}{|c|c|c|c|c|c|}
\hline \multirow[t]{2}{*}{ Question } & \multicolumn{4}{|c|}{ Response distribution $^{a}$} & \multirow{2}{*}{$\begin{array}{c}\begin{array}{c}\text { Correlatior } \\
\text { with age }^{b} \\
\rho\end{array} \\
\end{array}$} \\
\hline & Agree & & & Disagree & \\
\hline $\begin{array}{l}\text { It is a good idea that we write to } \\
\text { citizens using Digital Post }\end{array}$ & & & & & $.15^{* *}$ \\
\hline \multirow[t]{2}{*}{$\begin{array}{l}\text { It is a good idea that citizens can } \\
\text { write to us using Digital Post }\end{array}$} & & & & 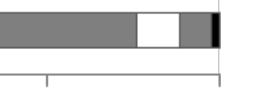 & $.12 *$ \\
\hline & $0 \%$ & $25 \%$ & $50 \%$ & $100 \%$ & \\
\hline
\end{tabular}

Figure 1. Overall attitude toward Digital Post

Notes. ${ }^{a}$ The response options were agree (left black), partially agree (left grey), neutral (white), partially disagree (right grey), and disagree (right black). ${ }^{\text {b }}$ Non-parametric Spearman rho correlation. $* p<.05, * * p<.01$.

At the incident level, only $53 \%$ of the respondents described situations of improved service, see Table 4. Thus, there was an almost even split between positive situations and the two kinds of negative situations. As much as $21 \%$ of the respondents described situations in which they had refrained from using Digital Post to avoid providing a degraded service to a citizen. We consider the number of incidents in which respondents refrained from using Digital Post noteworthy because these incidents indicated a level of dissatisfaction sufficient to influence the respondents' behavior and because local government was under considerable political pressure to use Digital Post. Also, the respondents' 
median rating of the frequency at which the described situations occurred was closer to 'very often' than 'very rarely' for positive as well as negative incidents, suggesting that the negative incidents contain lessons important to achieving widespread adoption of Digital Post.

Table 4. Concrete incidents with Digital Post

\begin{tabular}{lcccc}
\hline Perception of incident & \multicolumn{2}{c}{ Frequency } & & How often does this situation occur? ${ }^{\text {a }}$ \\
\cline { 2 - 3 } & $N$ & $\%$ & & Median \\
\hline Improved service with Digital Post & 239 & 53 & & 2 \\
Decreased service with Digital Post & 115 & 26 & & 2 \\
Refrained from using Digital Post & 94 & 21 & & 2 \\
\hline
\end{tabular}

Note. ${ }^{a}$ Respondents rated this question on a five-point scale with the end points 'very often' (1) and 'very rarely' (5).

\subsection{Overall attitude versus concrete incidents}

The difference between the respondents' positive perception of Digital Post at the relationship level and their more mixed perception at the incident level calls for analyzing the association between the two levels. Table 5 shows a breakdown of one of the overall-attitude questions and one of the frequency-of-use questions onto the three kinds of incident. We tested the association using Goodman and Kruskal tau, which indicates how much errors in the prediction of one variable are reduced given information about another variable (Costner, 1965). Knowing the kind of incident reduced errors in the prediction of agreement about whether it was a good idea to write to citizens using Digital Post by $11 \%(p<.001)$ : Respondents reporting an incident of improved service were, in general, slightly more in favor of the idea of writing to citizens using Digital Post. Knowing the kind of incident also reduced errors in the prediction of the frequency with which respondents sent Digital Post to citizens using the output manager, but only by $1 \%(p<.05)$. Thus, the association from incident to overall attitude was weak, and the association from incident to weekly use was negligible.

Table 5. Concrete incident versus overall attitude and frequency of use

\begin{tabular}{lccc}
\hline Perception of incident & $\begin{array}{c}\text { It is a good idea that we } \\
\text { write to citizens using } \\
\text { Digital Post }\end{array}$ & $\begin{array}{c}\text { How many times a week do you } \\
\text { use [the output manager] with a } \\
\text { social security number? }\end{array}$ \\
\cline { 2 - 3 } & Median & Median \\
\hline Improved service with Digital Post & Agree & $5-10$ \\
Decreased service with Digital Post & Partially agree & $5-10$ \\
Refrained from using Digital Post & Partially agree & $1-5$ \\
\hline
\end{tabular}

To explore the association between the relationship level and the incident level in more detail, we analyzed the association between the three kinds of incident and the eight questions about specific attitude elements, see Figure 2. These eight questions tapped issues known to influence people's acceptance of technology (Venkatesh et al., 2003). Knowing the kind of incident reduced errors in the prediction of the respondents' answer to the question "I provide better service to citizens when I use Digital Post" by $13 \%$. Thus, for this question there was a weak association between the incident level and the relationship level. For the seven other questions about specific attitude elements the association between the two levels was negligible, reducing prediction errors by only $1-6 \%$.

The respondents' median rating of the four questions in Figure 2 about performance expectancy and effort expectancy was full or partial agreement that Digital Post improved their performance and required an acceptable effort, thereby complementing the overall-attitude questions in Figure 1. For example, $75 \%$ of the respondents agreed, fully or partially, that they could accomplish their tasks 
more quickly using Digital Post. The two questions about social influence show that respondents strongly perceived an expectation from management to use Digital Post and tended to agree, at least partially, that their colleagues thought it was a good idea to use Digital Post. A Wilcoxon test comparing the respondents' overall attitude (first question in Figure 1) with their colleagues' overall attitude (fifth question in Figure 2) showed that respondents thought their colleagues were less in favor of using Digital Post than the respondents were themselves $(p<.001)$. This difference might indicate a difference between respondents and non-respondents or it might indicate a misperception of the colleagues' attitude as less favorable than it actually was. Finally, the first of the questions about facilitating conditions shows a somewhat mixed picture in that $27 \%$ of the respondents agreed, fully or partially, that rules, procedures and the like were barriers to their use of Digital Post, $22 \%$ were neutral, and $51 \%$ fully or partially disagreed. The second question about facilitating conditions indicated that Digital Post was generally experienced as well-integrated with the other systems used by local government.

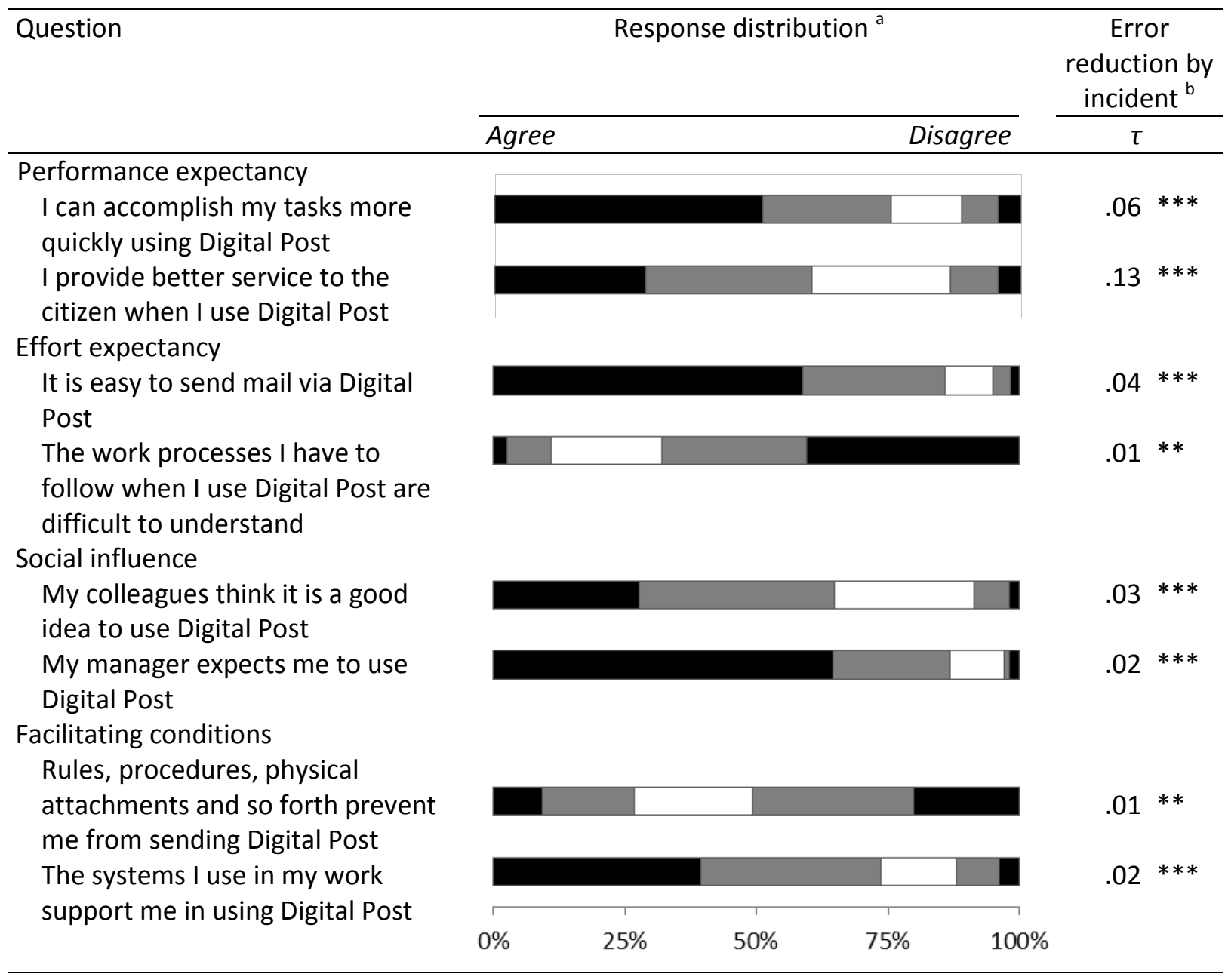

Figure 2. Detailed attitude

Notes. ${ }^{a}$ The response options were agree (left black), partially agree (left grey), neutral (white), partially disagree (right grey), and disagree (right black). ${ }^{\mathrm{b}}$ Goodman and Kruskal tau test with kind of incident as predictor variable. ${ }^{* *} p<.01,{ }^{* * *} p<.001$.

\subsection{Incidents with Digital Post}

The content of the incidents reported by the respondents fell into six categories: changes in service, attributes of citizens, changes related to staff, institution-level effects, staff-related operations, and 
citizen-related operations. The categories, elaborated in the following, add richness to constructs such as performance expectancy, effort expectancy, social influence, and facilitating conditions.

\subsubsection{Changes in service}

Changes in the service concerned the consequences for citizens of shifting the communication channel from physical letter to Digital Post. Digital Post was perceived as a better service when the citizen received the message more quickly and with less effort, thereby reducing the time to case completion. In addition, Digital Post enabled the respondent and the citizen to communicate more flexibly and swiftly and to collaborate on eliminating errors. This often compensated for rigid bureaucracy and benefitted the citizen. Digital Post also provided enhanced delivery assurance and documentation of the communication. Other sources of positive service changes perceived by respondents included around-the-clock access to the local government, independence of physical addresses, and the possibility of making written communication available to blind and dyslexic citizens:

"A blind citizen wanted the answer to his application for handicap aid in his Digital Post. This way, he could access the content of the letter by having his computer read the letter aloud and did not have to wait for his handicap assistant."

Respondents described decreased service when there was a demand from local government on the citizen or the citizen did not access Digital Post. Failure to access Digital Post could have a number of consequences. First, it could result in reminder fees if the citizen failed to notice an invoice (unpaid tax, resource consumption etc.) and additional reminder fees if the reminder remained unnoticed. Second, an offer that should be accepted within a deadline (daycare, nursing home etc.) was lost if not acted upon. Third, citizens might be summoned to meetings. For example, citizens that received unemployment benefits were summoned to meetings to ensure that they were actively searching for jobs. Failure to attend a mandatory meeting entailed a reduction in benefits. Fourth, an unnoticed Digital Post could lead to a delay in the commencement of a service to which a citizen was entitled. A respondent reported an incident of a mentally disabled young man who received all the documents needed for assistive care via Digital Post, but the assistive care was delayed for several months because he did not see the documents. Fifth, Digital Post was perceived as decreased service in situations where citizens were required to print the message from the local government but could not be expected to have access to a computer and printer:

"Most citizens that need help from the public sector are citizens that are not familiar with computers. Further, many cannot afford a computer. Moreover, a printer is also required. This may be excessive costs for many citizens. It is also my opinion that many that need help in most situations need personal contact with a case handler and due to the digitization, many local governments have cut off access to personal assistance."

\subsubsection{Attributes of the citizen}

In relation to the perceived change in service, respondents often mentioned attributes of the citizen. These attributes included IT skills, access to computer and Internet, whether the citizen was perceived as vulnerable (elderly, homeless, drug addict, psychiatrically ill, blind, dyslectic, migrant with limited knowledge of Denmark and Danish etc.) or was not motivated for digital communication. When these attributes were present, citizens were at risk of not noticing their Digital Post and, thereby, experiencing the negative service changes mentioned above. Respondents described very practical matters in the reported incidents, for example how citizens that were hospitalized had difficulty getting access to computers and how elderly citizens without relatives had little access to help with Digital Post. In addition, changes in a citizen's life situation (unemployment, divorce, illness etc.) could mean that the citizen was unable or unmotivated to meet the requirements of digital communication. Even citizens who were not considered vulnerable might not attend to Digital Post. 
Respondents reported that such lack of motivation had considerable influence on their perception of the change in service resulting from the use of Digital Post.

Respondents also reported that they mitigated the negative consequences for citizens by not using Digital Post in situations where they were in doubt about whether the citizen was able to access Digital Post and the communication was of great importance to the citizen. A respondent responsible for daycare administration reported how she reflected on parents' digital abilities: "[It] requires that the parents print the letter and send it back, or send an email to me. There are parents who will never get that done, it may be the very young parents, bilingual or low skilled. If I know in advance that it will not succeed, I will send a regular letter, so they have it in their mailbox and thereby can physically sign and deliver it at the municipality". In some cases, respondents even perceived Digital Post as counterproductive to the assistance of vulnerable citizens:

"For the dysfunctional, it [Digital Post] is a bad solution (addicts, very socially disadvantaged, homeless, mentally ill, etc.). Many of these fail to communicate in this way - they are unable to take responsibility about digital actions, do not have a computer or have no [Internet] access, they are not aware of the arrival of digital posts and, generally, have an unstable life. Often, it ends in a situation where the citizen must be sanctioned for failure to answer or no show - and this, of course, only makes the overall situation worse."

Respondents did not consider that the nation-wide possibility to access computers and Internet at the public libraries meant that the vulnerable citizens, in practice, had access to Digital Post in a way that made it a reliable means of communication.

\subsubsection{Changes related to staff}

This category covers incidents in which respondents described changes in their work situation. The majority of the incidents described a reduction or increase in workload. Respondents reported that it was much easier to send messages digitally with a few clicks than to print, sign, pack, and send a physical letter:

"I work with sickness benefits. Super, that we request/receive, for instance, declarations from GPs digitally. This really saves time. Furthermore, we summon citizens to meetings and send out personal recovery plans digitally. It saves a lot of time to be able to complete the work at your desk."

The shorter turnaround time for corrections of errors in collaboration with the citizen also reduced the cost for the respondents of returning to and completing cases.

The incidents of increased workload included citizens who were unsure whether their message had been received and phoned to be assured. Respondents also reported that they phoned or emailed citizens who had not reacted to Digital Post in situations where citizen action was required. Relatedly, respondents reported spending time locating documents they had previously sent digitally in order to print and physically send them to citizens in situations where written documentation was demanded by public institutions and the citizen had no printer. In addition, some citizens had difficulties attaching documents to their communications. These difficulties led to incomplete applications and a need for the respondent to contact the citizen again for further information and documentation:

"The vulnerable citizens with limited digital skills are more difficult to get into contact with using Digital Post. Often, they don't know that we have tried to send Digital Post to them. Consequently, they react to neither applications, nor rejections. Citizens that write to us often forget to attach the needed documents and this complicates the workflow because we need to write back to the citizen - possibly multiple times! Before this 'digital mantra', citizens came in person with all their documents or they 
phoned to be informed about what documents to provide. I contend that today I spend more time on a single case than I did six years ago."

When a deadline had not been met because a citizen had not checked Digital Post, additional work was created for respondents who either had to stop benefits or to restore the situation for the citizen. Finally, Digital Post was not designed for workflows involving multiple actors, for example a document that must be signed by a citizen as well as his or her employer. Similarly, a physical letter that could previously be send to the address of a family, where both adults would have access to it, now had to be send as two messages, one to each adult. Some respondents were very conscious about when not to rely solely on Digital Post and spent considerable resources on these cases. One respondent, administering offers for nursing homes to elderly citizens, stated that "I always call the relatives to make them aware that there is an offer in the Digital Postbox".

The positive changes in the respondents' work situation were connected to the situations in which Digital Post improved the service delivered to citizens. Conversely, the increases in staff workload were connected to incidents in which the respondents also perceived reduced service to citizens who, for some reason, were not able to manage digital communication.

\subsubsection{Institution-level effects}

The respondents reported institution-level effects of Digital Post but they provided less detail about this category than about the other five. The institution-level effects included reduced costs (stamps, paper, and work time) and enhanced flexibility leading to a productivity increase. Respondents described the reduced costs and enhanced flexibility as the political drivers of Digital Post. Most of the descriptions of institutional effects were positive but there were also respondents who expressed that the use of Digital Post was costly and hampered flexibility. Both viewpoints can be true. Some respondents argued that allocated time was wasted when citizens did not show up because they had missed a message in Digital Post, whereas other respondents argued that Digital Post enabled the flexibility necessary to summon another citizen. Most respondents acknowledged that Digital Post led to cost reductions but some respondents argued that they now spent more time than before and that the saved stamps could not cover the increase in operational time.

\subsubsection{Staff-related operations}

Staff-related operations concerned how the technology that interacted with Digital Post supported or hindered the work processes involved in the digital communication with citizens. This category is different from the one about changes in the staff's work situation in the way that the category about staff-related operations does not imply any change in the work situation - the respondents merely described how technology did or did not support their work.

Messages in Digital Post were perceived as easy to archive and easy to retrieve later for renewed use. Respondents also emphasized the time savings resulting from the integration of mail-merge functionality and from the ability of the output manager to distinguish automatically between citizens who should receive a digital letter or a physical letter. A respondent from an urban planning department described a work process that previously took several employees a whole day:

"Today, the employee writes a cover letter with the URL for the plan, extracts names and addresses from the GIS system to Excel and the lot is being mail merged as usual, but now it takes one click and under 15 minutes for one employee to send all the messages. The citizen can see the plan instantly [and easily from the URL], may send their comments electronically and need not send a physical letter. Citizens are happy to avoid the many papers in the mail, the employees save time, we save postal costs and rainforest - it is a clear win-win."

The respondents also reported incidents in which messages were hard to locate, resulting in late or no answers to citizens. The absence of receipts from Digital Post impeded the documentation 
process and future case handling. Attachments were hard to handle in Digital Post, and Digital Post was poorly integrated with the many systems that generated attachments for Digital Post. In addition, Digital Post provided limited support for work processes that involved actors other than the citizen and the local government (GP, police, court, hospital, a citizen trustee etc.) or parties that only accepted physical letters (e.g., because signatures were not considered authentic if scanned):

"I work with forms for citizens in other countries - this is cumbersome. The workflow might be that the form is filled out on the computer, printed, stamped, and signed because foreign authorities demand the 'original'. Then, the form is scanned because I must archive it digitally on the citizen's case."

Finally, respondents reported that citizens who sent messages to local government sometimes chose a wrong recipient because the local government's Digital Postboxes were not intuitively named. These incidents led to manual internal delivery of messages from one department to another.

\subsubsection{Citizen-related operations}

Citizen-related operations were the operations that citizens must perform to use Digital Post. The incidents reported by respondents in this category focused primarily on how the use of Digital Post was hampered by the technology that surrounded Digital Post. Respondents described that some citizens found Digital Post difficult to set up and operate. One source of confusion was the similarity between Digital Post and the similar system e-Boks; citizens did not understand the difference between the two systems. Access to Digital Post by means of NemID was another source of complexity, including difficulties with activation, re-activation (when citizens' initial attempt to activate failed), login, Java updates, operating-system updates, and the establishment and maintenance of an Internet connection. Also, file attachments, printers, and scanners were reported to cause some citizens problems:

"I often experience that citizens have problems when they need to attach documents. Many don't have a scanner or they have one but don't know how to operate it - how they scan the document, how they save it, or how they attach it. Most people know how to operate basic technologies, but if it gets too technical, we lose them."

Citizens also had problems setting up alerts so that they would get a text or email notification when they received new messages in Digital Post. Several incidents revealed how Digital Post hampered the sharing of information among citizens. For example, relatives could previously sort elderly people's physical mail when visiting but did not see or even have access to the elderly people's messages in Digital Post. One respondent noted that "you can't just share the letter in the same way as if it was just lying on the kitchen table" and another that "if you are hospitalized, you can't ask your neighbor to empty the mailbox".

\section{Discussion}

\subsection{Digital communication with citizens is good service but...}

The majority of the respondents think it is a good idea to communicate with citizens using Digital Post (Figure 1). It must be assumed that this finding facilitates the adoption of Digital Post because a positive attitude to the system increases the likelihood that the respondents, as local government staff, adopt Digital Post themselves and serve as champions of Digital Post toward the citizens. The respondents' positive attitude toward Digital Post is supported by their indications of how much they use Digital Post: They send digital letters to citizens at least as often as they send physical letters. The respondents' indications of their use of Digital Post are supported by Andersen et al. (2011) who found that Danish local governments responded promptly and, for the most part, adequately to email from citizens. However, Berger and Andersen (2013) found that when they, under the pretense of being a citizen, contacted local government by Digital Post, rather than by conventional email, 
only half of the local governments responded. This may suggest that local governments, at present, mainly see Digital Post as a means of government-initiated communication with citizens.

At the relationship level, the respondents find that they can accomplish their tasks more quickly and provide better service to citizens when they use Digital Post, and that using Digital Post is easy and supported by the other systems they use in their work (Figure 2). In addition, they strongly perceive an expectation from their management to use Digital Post. Thus, with respect to their own use of the system, the respondents perceive that all four factors in the unified technology acceptance model (Venkatesh et al., 2003) are positively present. These findings are consistent with the respondents' overall perception that it is a good idea to communicate with citizens using Digital Post. Notably, this perception is more strongly held by younger respondents, just as Shin (2012) found that decreased age correlated with increased use of e-government among local public managers. When the respondents express reservations against Digital Post it is mostly because they perceive that certain groups of citizen are unable to use it or must be expected not to notice communication via Digital Post. For groups such as elderly, homeless, or otherwise vulnerable citizens the respondents give multiple examples of situations in which they consider Digital Post inappropriate. In $21 \%$ of the reported incidents, the respondents refrained from using Digital Post because they considered it inappropriate in the situation; in another $26 \%$ of the incidents respondents used Digital Post but felt that it degraded the service delivered to the citizen. These incidents illustrate the tension experienced by respondents between Digital Post, the use of which is increasingly mandated in localgovernment procedures, and the provision of good service to citizens. Following Roman (2013) and Wastell et al. (2009), the tensions are, probably, experienced as especially troubling because they tend to hit the most vulnerable citizens the hardest.

The near even split between incidents reporting improved service and incidents reporting negative consequences emphasizes that the respondents' positive overall attitude is an aggregate of a mix of issues. This finding is formally expressed in the weak statistical associations between responses to questions at the relationship and incident levels. While the reported incidents are not representative of the respondents' overall attitude, we contend that they are accurate. The issues described in the incidents show that Digital Post is not flawless but the flaws are, for the most part, not sufficiently severe to determine the respondents' overall perception of the system. Their overall attitude is, instead, primarily determined by other factors, which may for example include a general belief that government benefits from technology. Because informal conversations often include concrete incidents as examples (Edvardsson \& Strandvik, 2000), the discrepancy between respondents' overall attitude and concrete incidents may suggest that Digital Post is portrayed in an overly negative manner in informal conversations compared to people's overall attitudes. This provides a possible explanation of our finding that the respondents, on average, perceived their colleagues as less in favor of using Digital Post than they were themselves. It also shows the value of having data at the relationship level as well as the incident level.

\subsection{Content categories in staff perception of e-government service}

The incidents contained six categories of content, namely changes in service, attributes of citizens, changes in the staff's work situation, institution-level effects, staff-related operations, and citizenrelated operations. The categories underline the complexity and interdependencies involved in providing e-government services. Thereby, the categories also show the multiplicity of factors needed in models of e-government adoption. For example, the category about changes in service points toward factors from service quality models (Parasuraman et al., 2005). The category about the citizens points toward factors emphasized by Shin (2012) in his discussion of public managers' commitment to public service. And the category about the staff points toward factors such as workload. In particular, Digital Post is perceived as contributing both positively and negatively to the service delivered to citizens. The perception of positive impact originates from reduced staff workload and institutional cost savings and is, thus, related to both system quality and information quality. This accords with a study of a similar system in Taiwan (Sun et al., 2006) and with the positive 
effects generally expected from e-government. Our study also shows how e-government can enhance staff-citizen collaboration and, thereby, mitigate the consequences of otherwise bureaucratic procedures or create new services. It is the co-occurrence of appropriate technologies, capable citizens, motivated staff, and relevant communication content that leads to the perceived service improvements, workload reductions, and increases in efficiency. Digital Post as such neither improves service nor increases efficiency.

The incidents reporting decreased service reveal that the service decrease may take multiple forms, including increased fees, reduced benefits, delayed assistance, difficult-to-share documents, requirements for the citizen to print government documents, and expenses for computer, printer, and Internet access. The perception of decreased service is often related to what the respondents call vulnerable citizens. The respondents find that in a number of situations Digital Post works against treating the citizens equally. Consistent with the evolution in the discourse about the digital divide (Helbig et al., 2009), the inequalities introduced by Digital Post are at least as much about the vulnerable citizens' inability to make use of Digital Post as they are about their lack of access to the required technologies. Our results show that even countries with a high level of e-government provision struggle with the digital divide, as previously asserted by Dwivedi et al. (2012). From a narrow point of view the inability is a result of inadequate skills and can be addressed by education and training. However, the respondents explain the vulnerable citizens' inability to make use of Digital Post by their general life situation, such as being elderly, suffering from psychiatric illness, or having poor command of Danish. This shifts the reasons for the inability to a much more complex set of issues. In addition, respondents describe incidents with citizens who lack the motivation to use Digital Post. These incidents resemble the finding by Hakkarainen (2012) that some people just do not see any use for information technology in their everyday life and, therefore, choose to be nonusers. It is a sensitive issue whether making the use of Digital Post mandatory is fair to the vulnerable citizens. The respondents' negative reactions to Digital Post are mainly related to these citizens and indicate that respondents do not perceive it as fair.

Whereas Shin (2012) showed that a high staff commitment to public service had a positive impact on technology adoption, our data suggest that the relation between public service commitment and technology adoption is moderated by the staff's perception of the quality of the service: 94 respondents reported incidents where they had refrained from using Digital Post to avoid providing a service they perceived as too poor. The modest adoption of digital communication between government staff and citizens (Berger \& Hertzum, 2014; Sun et al., 2006) may, in part, be explained by an incompatibility between staff values and the values incorporated in digital communication. Such an explanation would be in line with Rogers (2003).

Respondents reported multiple incidents in which Digital Post increased rather than decreased workload. Increased workload was experienced in incidents involving vulnerable citizens, degraded service, and technology that did not support the operations involved in the task. There were multiple sources of the workload increase. First, staff must help citizens understand and master the technology, and when they do not, staff must correct the resulting errors. Second, various basic operations are not supported by the technology. These operations must be performed manually in order to use Digital Post. Third, communications that involve multiple actors (different public and private institutions) or multiple individuals (apart from the citizen) or include non-digital processes are not supported well by Digital Post. Fourth, limited integration of Digital Post with other technologies creates extra work. Fifth, inadequate configuration of Digital Post requires internal message transfers that are extra work and delay case handling. Sixth, citizens cannot share a message in Digital Post as easily as they can share a physical letter, thereby causing extra work, or breakdowns, at the citizen's end. These barriers underline the finding by Irani et al. (2007) about technology sometimes being the problem. 


\subsection{Implications for research and practice}

We see five implications of our study for research on e-government. First, the respondents perceive speed and ease to be the main advantages of digital communication with citizens. In a number of cases speed is integral to service quality because it enables citizens to meet tight deadlines or government staff to request supplementary information without delaying the case. In other cases, speed and ease appear to be considered virtues in their own right. The primary focus on speed and ease may be indicative of the transaction stage, of which Digital Post is an example. The finding by Shareef et al. (2011) that different factors influenced citizens' adoption of e-government services at different stages should also be investigated for government staff's adoption of e-government.

Second, the citizen's situation is important to the staff's perception of whether a service like Digital Post is good service. This aspect of the respondents' perception of Digital Post appears insufficiently captured by the technology-acceptance models, which focus on an individual's own use of a system, and warrants supplementing such models with models of service quality in future studies of staff adoption of e-government. The influence of the citizen's situation on the staff's perception and adoption of e-government may be culture dependent and stronger in countries that are high on what Hofstede (2001) terms femininity. Femininity, which emphasizes values such as caring for others, is high in, for example, Denmark and Sweden but low in countries such as Germany and the US.

Third, assessments of e-government and other services at the relationship and incident levels target different aspects of the service. This finding, supported by previous studies (e.g., Edvardsson \& Strandvik, 2000; Odekerken-Schröder et al., 2000), has important methodological implications. For example, assessments at the incident level cannot be taken as indicative of overall attitudes at the relationship level. Thus, the common practice of asking interviewees for concrete examples may provide rich detail and accurate diagnostic information but it is questionable to use counts of positive and negative examples as indicative of overall attitude or to identify top barriers to e-government adoption on the basis of the frequency of such examples.

Fourth, the concrete incidents described by respondents show the diversity of the real-world situations into which systems like Digital Post are introduced. We are concerned that e-government research may pay insufficient attention to this diversity and, thereby, to the situated action required to deliver good service to citizens. Survey-based studies, such as ours, are popular in e-government research but limited in their receptiveness to the rich detail necessary to appreciate diversity and situated action. To some extent this limitation amounts to black-boxing the very issues we need to understand in a research field concerned with how technology may enable, and otherwise affect, interactions between government and citizens. Ethnographic studies (e.g., Pors, 2015) may complement survey-based studies by providing insights into the multiple ways, intended as well as unintended, in which government, citizens, and technologies transform each other.

Fifth, it is appropriate to consider the relevance of our findings to countries other than Denmark because different countries have taken different strategic approaches (Dwivedi et al., 2012). A key characteristic of Digital Post is that its business case speaks in terms of savings and efficiency from a top-down perspective, but that the respondents' perception of Digital Post is shaped by a richer set of factors, including whether it delivers good service to citizens. Similar tensions have been reported from e-government studies in the UK (Irani et al., 2007; Wastell et al., 2009) and more generally (Roman, 2013). These tensions point to important value conflicts. While the particular incidents described by our respondents are specific to Denmark, we contend that they exemplify concerns and consequences of more general relevance. This contention must, however, be tested in future empirical work.

In terms of implications for practice, we want to emphasize four issues that are important in achieving the intended effects from e-government initiatives such as Digital Post: 
- In spite of an overall positive attitude toward the use of a system, staff may still refrain from using it in a number of situations. These situations may be sufficiently numerous to warrant system changes or a reconsideration of the intended effects.

- Staff is sensitive to tensions between the provision of good service to citizens and the consistent use of mandated systems. For vulnerable citizens they will often try to compensate for a rigid system, thereby possibly annulling intended effects.

- Local governments are likely to mature slowly with respect to e-government because the barriers to full adoption are politically charged and because the partial adoption of one system at one maturity stage will tend to block or delay other systems at successive stages.

- Local governments should draw on their staff's rich experiences with overcoming barriers and revising work processes in the day-to-day use of e-government and on their decisions about when it is not appropriate to use, for example, Digital Post.

\subsection{Limitations}

Four limitations should be remembered in interpreting the results of this study. First, while the 448 respondents are representative of the population of local government staff with respect to key demographic variables, they form a modest sample compared to the size of the full population. We cannot rule out that the respondents' perception of Digital Post differs, in some respects, from that of the full population of local government staff. Second, this study investigates local government staff's perception of Digital Post. The local government staff is a central user group of Digital Post and in a privileged position to assess its influence on their work but they merely provide one stakeholder's view on whether Digital Post is good service to citizens. We acknowledge that this study does not investigate how citizens perceive Digital Post. Third, we conducted our survey half a year before the use of Digital Post became mandatory for citizens. It caused some public debate that Digital Post was to replace physical letters in the communication between local government and citizens. This debate may have sharpened the respondents' awareness of the possible implications of Digital Post and, in particular, sensitized them to citizens who were overwhelmed or distressed by the prospect of digital communication with their local government. Fourth, this study is based on a survey and we already touched upon the limitations of survey-based studies in the previous section. Specifically, the data about the respondents' weekly use of Digital Post are self-reported by the respondents. Thus, our finding that at least as many digital as physical letters are sent to citizens reflects the respondents' perception of how many digital and physical letters they send. For actual counts of the number of digital (and physical) letters sent by Danish municipalities, see Berger and Hertzum (2014).

\section{Conclusion}

We have surveyed local government staff's perception of how their communication with citizens is affected by the Danish e-government initiative Digital Post. At the relationship level, $82 \%$ of the 448 respondents were in favor of digital communication with citizens using Digital Post. However, at the incident level the respondents were about evenly divided between those describing an incident in which Digital Post improved the service delivered to the citizen and those describing an incident of decreased service. For $21 \%$ of respondents the decrease in service had been perceived as so severe that they in the reported incident had refrained from using Digital Post. The distinction between the relationship level and the incident level is conceptually important because the two levels capture different aspects of how a service is perceived. Furthermore, it is methodologically important because the association between the two levels is inadequately understood, and it is practically important because confusion of assessments at one level for the other may lead to differing conclusions. E-government research has mostly focused on the relationship level, thereby leaving the concrete sources of staff's and citizens' perception of e-government under-researched. 
We extracted six content categories from the respondents' incident descriptions to map out the sources underlying their perception of Digital Post. The categories concerned the perceived change in service, the citizen's readiness to digital communication, the change in the staff's work situation, the institutional effects, and how the technology supported or hampered the operations to be performed by the staff and by the citizen. Perceived negative changes in service resulted from lost welfare benefits, service delays, and reduced possibilities for sharing the communication with others. These negative changes may especially impact vulnerable citizens. In addition, the negative changes in service related to perceived increases in staff workload because the staff must assist citizens in digital communication. Finally, the study reveals that the operations that staff and citizens need to perform to communicate digitally are in a number of situations hampered by technological issues such as lacking interoperability, flawed configurations, and misalignment with work processes.

In November 2014 it became mandatory for Danish citizens to communicate with public sector institutions using Digital Post rather than physical letters. This transition multiplied the implications good and bad - of Digital Post.

\section{Acknowledgements}

We are grateful to HK for distributing the invitation to take part in the survey. We declare that apart from distributing the survey on our behalf, HK had no influence on or role in the survey. Special thanks are due to the local government staff for sharing their perception of Digital Post with us.

\section{Appendix: Survey instrument}

\begin{tabular}{|c|c|}
\hline Question & Scale \\
\hline \multicolumn{2}{|l|}{ Use of digital and non-digital communication } \\
\hline $\begin{array}{l}\text { How many times a week do you use the Digital Post button in } \\
\text { Outlook? }\end{array}$ & $0,1-5,5-10,10-50,50+$ \\
\hline $\begin{array}{l}\text { How many times a week do you use the output manager with a } \\
\text { social security number? }\end{array}$ & $0,1-5,5-10,10-50,50+$ \\
\hline $\begin{array}{l}\text { How many times a week do you use the output manager without a } \\
\text { social security number? }\end{array}$ & $0,1-5,5-10,10-50,50+$ \\
\hline How many times a week do you send a physical letter? & $0,1-5,5-10,10-50,50+$ \\
\hline \multicolumn{2}{|l|}{ Overall attitude toward Digital Post } \\
\hline It is a good idea that we write to citizens using Digital Post & 5-point, agree-disagree \\
\hline It is a good idea that citizens can write to us using Digital Post & 5-point, agree-disagree \\
\hline $\begin{array}{l}\text { It is good that the citizen can apply for an exemption from } \\
\text { registration for Digital Post }\end{array}$ & 5-point, agree-disagree \\
\hline $\begin{array}{l}\text { It is good that the citizen has to visit the municipality physically to be } \\
\text { exempted }\end{array}$ & 5-point, agree-disagree \\
\hline I think it is realistic that $80 \%$ of communication can be digitized & 5-point, agree-disagree \\
\hline \multicolumn{2}{|l|}{ Concrete incident with Digital Post } \\
\hline $\begin{array}{l}\text { Describe a concrete situation in which you have experienced that } \\
\text { Digital Post changes the service delivered to the citizen. It may be a } \\
\text { situation where your use of Digital Post has improved the service or } \\
\text { decreased the service or a situation where you have refrained from } \\
\text { sending Digital Post because you believed it would be bad service to }\end{array}$ & Text \\
\hline
\end{tabular}


the citizen.

The change in service to the citizen in the situation described

1 Improved service with Digital Post, 2 Reduced service with Digital Post, 3 Did not use Digital Post to avoid poor service

How often does this situation occur?

5-point, often-seldom

The description may be published in anonymized form?

Specific attitude toward Digital Post

I can accomplish my tasks more quickly using Digital Post

I provide better service to the citizen when I use Digital Post

It is easy to send mail via Digital Post

The work processes I have to follow when I use Digital Post are difficult to understand

My colleagues think it is a good idea to use Digital Post

Yes, no

5-point, agree-disagree

5-point, agree-disagree

5-point, agree-disagree

5-point, agree-disagree

5-point, agree-disagree

My manager expects me to use Digital Post

Rules, procedures, physical attachments and so forth prevent me from sending Digital Post

The systems I use in my work support me in using Digital Post Demographics

Work place

Age

Gender

Work domain

5-point, agree-disagree

5-point, agree-disagree

5-point, agree-disagree

List of municipalities and regions

Integer

Male, female

List

How long have you worked with your current work?

$0-1,1-5,5+$ years

Other

I should like to be contacted for any clarifying questions (please provide contact details in the comment field)

I would like to receive the results of the study

yes, no

yes, no

Comments on the study, including contact information (email,

Text phone ) if you have answered 'yes' to either of the two preceding questions

\section{References}

Al Thunibat, A., Zin, N. A. M., \& Sahari, N. (2011). Identifying user requirements of mobile government services in Malaysia using focus group method. Journal of e-Government Studies and Best Practices, 2011, 1-14.

Andersen, K. N., Medaglia, R., Vatrapu, R., Henriksen, H. Z., \& Gauld, R. (2011). The forgotten promise of e-government maturity: Assessing responsiveness in the digital public sector. Government Information Quarterly, 28(4), 439-445.

Bannister, F., \& Connolly, R. (2014). ICT, public values and transformative government: A framework and programme for research. Government Information Quarterly, 31(1), 119-128. 
Barbosa, A. F., Pozzebon, M., \& Diniz, E. H. (2013). Rethinking e-government performance assessment from a citizen perspective. Public Administration, 91(3), 744-762.

Baumeister, R. F., Bratslavsky, E., Finkenauer, C., \& Vohs, K. D. (2001). Bad is stronger than good. Review of General Psychology, 5(4), 323-370.

Bélanger, F., \& Carter, L. (2009). The impact of the digital divide on e-government use. Communications of the ACM, 52(4), 132-135.

Berger, J. B., \& Andersen, K. N. (2013). Digital communication with the public sector: Main results from the study on response and response times in municipalities, counties, State agencies and State departments (Danish). Aalborg: Aalborg University.

Berger, J. B., \& Hertzum, M. (2014). Adoption patterns for the digital post system by Danish municipalities and citizens. In ECIS2014: Proceedings of the 22nd European Conference on Information Systems, Atlanta, GA.

Bitner, M. J., Booms, B. H., \& Tetreault, M. S. (1990). The service encounter: Diagnosing favorable and unfavorable incidents. Journal of Marketing, 54(1), 71-84.

Cohen, J. (1960). A coefficient of agreement for nominal scales. Educational and Psychological Measurement, 20(1), 37-46.

Costner, H. L. (1965). Criteria for measures of association. American Sociological Review, 30(3), 341353.

Dwivedi, Y. K., Shareef, M. A., Simintiras, A. C., Lal, B., \& Weerakkody, V. (2015). A generalised adoption model for services: A cross-country comparison of mobile health (m-health). Government Information Quarterly.

Dwivedi, Y. K., Weerakkody, V., \& Janssen, M. (2012). Moving towards maturity: challenges to successful e-government implementation and diffusion. ACM SIGMIS Database, 42(4), 11-22.

Edvardsson, B., \& Strandvik, T. (2000). Is a critical incident critical for a customer relationship? Managing Service Quality, 10(2), 82-91.

Flanagan, J. C. (1954). The critical incident technique. Psychological bulletin, 51(4), 327-358.

Gremler, D. D. (2004). The critical incident technique in service research. Journal of Service Research, $7(1), 65-89$.

Hakkarainen, P. (2012). 'No good for shovelling snow and carrying firewood': Social representations of computers and the internet by elderly Finnish non-users. New Media \& Society, 14(7), 11981215.

Heeks, R., \& Bailur, S. (2007). Analyzing e-government research: Perspectives, philosophies, theories, methods, and practice. Government Information Quarterly, 24(2), 243-265.

Helbig, N., Gil-Garcia, J. R., \& Ferro, E. (2009). Understanding the complexity of electronic government: Implications from the digital divide literature. Government Information Quarterly, 26(1), 89-97.

Hofstede, G. (2001). Culture's consequences: Comparing values, behaviors, institutions, and organizations across nations. Second edition. Thousand Oaks, CA: Sage.

Irani, Z., Al-Sebie, M., \& Elliman, T. (2006). Transaction stage of e-government systems: identification of its location and importance. Paper presented at the 39th Annual Hawaii International Conference on System Sciences, 2006 (HICSS'06), Koloa, Hawaii

Irani, Z., Elliman, T., \& Jackson, P. (2007). Electronic transformation of government in the UK: A research agenda. European Journal of Information Systems, 16(4), 327-335.

Janowski, T. (2015). Digital government evolution: From transformation to contextualization. Government Information Quarterly, 32(3), 221-236.

Krosnick, J. A. (1999). Survey research. Annual Review of Psychology, 50, 537-567.

Law about Public Digital Post. (2012). L528 (Danish). Copenhagen, Denmark: Ministry of Justice.

Layne, K., \& Lee, J. (2001). Developing fully functional E-government: A four stage model. Government Information Quarterly, 18(2), 122-136.

Lazar, J., Feng, J. H., \& Hochheiser, H. (2010). Research methods in human-computer interaction. West Sussex: Wiley. 
McKnight, D. H., Choudhury, V., \& Kacmar, C. (2002). Developing and validating trust measures for ecommerce: An integrative typology. Information Systems Research, 13(3), 334-359.

Ministry of Finance. (2012). Agreement on the municipal economy 2013 (Danish). Copenhagen, Denmark: Ministry of Finance.

Norris, D. F., \& Reddick, C. G. (2013). Local E-Government in the United States: Transformation or Incremental Change? Public Administration Review, 73(1), 165-175.

Odekerken-Schröder, G., van Birgelen, M., Lemmink, J., de Ruyter, K., \& Wetzels, M. (2000). Moments of sorrow and joy: An empirical assessment of the complementary value of critical incidents in understanding customer service relationships. European Journal of Marketing, 34(1\&2), 107-125.

Parasuraman, A., Zeithaml, V. A., \& Berry, L. L. (1988). SERVQUAL: A multiple-item scale for measuring consumer perceptions of service quality. Journal of Retailing, 64(1), 12-40.

Parasuraman, A., Zeithaml, V. A., \& Malhotra, A. (2005). ES-QUAL a multiple-item scale for assessing electronic service quality. Journal of Service Research, 7(3), 213-233.

Pors, A. S. (2015). Becoming digital-passages to service in the digitized bureaucracy. Journal of Organizational Ethnography, 4(2), 177-192.

Rana, N. P., \& Dwivedi, Y. K. (2015). Citizen's adoption of an e-government system: Validating extended social cognitive theory (SCT). Government Information Quarterly, 32(2), 172-181.

Rana, N. P., Dwivedi, Y. K., \& Williams, M. D. (2013). E-government adoption research: an analysis of the employee's perspective. International Journal of Business Information Systems, 14(4), 414428.

Rana, N. P., Dwivedi, Y. K., \& Williams, M. D. (2015). A meta-analysis of existing research on citizen adoption of e-government. Information Systems Frontiers, 17(3), 547-563.

Robertson, S. P., \& Vatrapu, R. K. (2010). Digital government. Annual Review of Information Science and Technology, 44, 317-364.

Rogers, E. M. (2003). Diffusion of Innovations, Fifth edition. New York: The Free Press.

Roman, A. V. (2013). Framing the questions of e-Government ethics: An organizational perspective. The American Review of Public Administration, 45(2), 216-236.

Schaeffer, N. C., \& Presser, S. (2003). The science of asking questions. Annual Review of Sociology, 29, 65-88.

Shareef, M. A., Kumar, V., Kumar, U., \& Dwivedi, Y. K. (2011). e-Government adoption model (GAM): Differing service maturity levels. Government Information Quarterly, 28(1), 17-35.

Shin, E. (2012, 4-7 January). Attitudinal Determinants of E-Government Technology Use among U.S. Local Public Managers. In 45th Hawaii International Conference on System Sciences (HICSS-45), Maui, HI, USA.

Stauss, B., \& Weinlich, B. (1997). Process-oriented measurements of service quality: Applying the sequential incident technique. European Journal of Marketing, 31(1), 33-55.

Sun, S.-Y., Ju, T. L., \& Chen, P.-Y. (2006). E-government impacts on effectiveness: a survey study of an e-official-document system. Electronic Government: An International Journal, 3(2), 174-189.

Urquhart, C., Light, A., Thomas, R., Barker, A., Yeoman, A., Cooper, J., . . Spink, S. (2003). Critical incident technique and explicitation interviewing in studies of information behavior. Library \& Information Science Research, 25(1), 63-88.

Venkatesh, V., Morris, M. G., Davis, G. B., \& Davis, F. D. (2003). User acceptance of information technology: Toward a unified view. MIS Quarterly, 27(3), 425-478.

Wastell, D., White, S., \& Broadhurst, K. (2009). The Chiasmus of Design: paradoxical outcomes in the e-Government reform of UK Children's Services. In IFIP WG 8.2 International Conference: Information Systems-Creativity and Innovation in Small and Medium-Sized Enterprises, CreativeSME 2009, Berlin. 